\title{
THE COMMON GROUND OF THERMAL BATHS
}

\author{
ELEONORA FIORENTINO, SUSANNA CURIONI \& CARLO PISANO \\ Department of Civil and Environmental Engineering and Architecture, University of Cagliari, Italy
}

\begin{abstract}
To consider water as a common good means to intend to address not only the natural resource, but also the ability to use it and the rights that a community has to enjoy that resource. Furthermore, water is seen not only as the basis for human existence, but also as a source of metaphysical symbolism, aesthetic pleasure, having therapeutic values. In fact, water is closely linked to the concept of the bath in both its main forms: one devoted exclusively to cleaning, a personal and private matter; and the other as a restoring activity and the centre of social life and of the community. To this second category belong the thermal baths that are able to reveal, through different forms, local traditions and identities. Sardinia is one of the most promising regions of Italy for the exploitation of geothermal resources, with the presence of numerous thermal sources. Thermal springs, spread over the island's territory, revealing their ancient origins with different characteristics: sites included in consolidated urban contexts (Sardara, Fordongianus) and point elements scattered throughout the landscape (Benetutti, Dorgali) represent the memory of structures that over the centuries have constituted important opportunities to generate spaces for the community. This paper illustrates, within the thermal bath system of Sardinia, three cases where the thermal waters can be considered a common good, while also investigating the relationship between spatial structures and the resource management process.
\end{abstract}

Keywords: baths, common resources, community rights, geothermal resources, Italy, Sardinia, springs, thermal waters, water system.

\section{INTRODUCTION}

In the context of Sardinia (one of the main islands of the Mediterranean), this paper proposes a reinterpretation of thermal resources, considering them as a common good capable of establishing strong connections with the territory and the community, both the local one and with the tourist.

In the first part, we attempt to define what is a common resource, in which way it has been investigated and defined over time, and what are its essential features. The second part of the paper considers water as a common resource to be preserved and the thermal baths as a possibility of being a safeguard and enhancement of water resources, as well as a place for public life and social relations. In the third part, we present the context of reference, namely that Sardinia and its thermal system is constituted of varied landscapes in terms of locations and is characterized by a diversity both in use and in management of the thermal resource.

Within the thermal Sardinian landscape, three study cases were chosen for the way they manage their thermal resources, which reflects the concept of common usage. These three places were presented in the fourth part of the paper and have been investigated with respect to landscape features, the context, the distribution of the thermal springs and their relationship between these two aspects and the type of thermal water management.

This paper ends with a reflection on three different ways to decline the water, according to a logic that is related to the definition of common areas, concerning both the physical and cultural characteristics of their contexts, particularly with respect to the thermal hot springs, and the customs and practices that have become consolidated within the communities. 


\section{A DEFINITION OF COMMONS}

"What is common to the greatest number has the least care bestowed upon it. Everyone thinks chiefly on his own, hardly at all of the common interest" [1].

The debate on the commons already aroused the interest of Aristotle, and over the last 40 years, the passing of the alternatives between public and private, as well as the openness to the concept of what is common, has become a central theme in many disciplines; from those linked to the economic and political sciences and psychological dynamics, to those who deal with the territory.

The concept of common areas, therefore, has distant origins, those where the ancient Romans considered earth, water, air, sky, flora, fauna and the navigable waterways as common things or res communes. More recently, in a special issue of 'The Ecologist' in 1992, the commons were defined as "a system of social relations based on cooperation and reciprocal dependency that provide sustenance, security and independence, yet typically do not produce commodities" [2]. Thus, a first characteristic of commons is that they are goods, resources, but are not commodities and not subject to market rules.

The commons are, in fact, flexible, and capable of changing to adapt to different challenges related both to the environment and technologies, are an expression of undeniable human rights and of the need for cooperation and social relations. This diversity and flexibility allows a more conscious use of the natural resources upon which the commons themselves depend, by avoiding their over-exploitation, degradation and destruction, which are, instead, inevitable consequences of the capitalist system. Therefore, another feature of commons is the 'local systems' dimension, which means it can be managed effectively by those who have a precise and detailed knowledge of the place, its history, language, culture and physical components; however, belonging to a 'local' reality does not mean that commons are elements that are isolated either in time nor space, as their social organization is not static. They are open local systems, receptive and adaptable to local 'whims' such as climate, the different attributes of the localities in terms of natural resources, the knowledge of the inhabitants and their professionalism [2].

Western capitalist development was based, instead, on the pillaging of common areas. One of the most complex problems faced by contemporary society is, in fact, to give priority to the dimension of being, rather than having. The attention and the full understanding of the common areas allows people to see a different reality, the possibility of different social relations based on the satisfaction of needs related to being, and not only to having. "We do not have a common (an ecosystem, water) but in a sense, we are (part of) a common (we are water, we are part of an urban or rural ecosystem)" [3]. The commons, therefore, require a holistic perception that can fully capture the essential links with the local community and with other nearby communities.

Unlike the logic of the market, the dynamics which govern the commons (both in their physical and cultural nature) are not produced by exclusion, but inclusion: goods are accessible to all. The common good is not based on a "rival consumption"; on the contrary, it is characterized by a "relational consumption" that enhances its value through a qualitatively responsible use [3]. Another aspect to look for in a common good, then, is the universal principle of accessibility. The commons belong to us all; but, at the same time, do not belong to anyone, in the sense that no one can prevent access to common areas. In the commons, management creates, thus, reciprocal bonds, collective solidarity constraints, rules that create community, cohesion and identity. In other words, we could say that the struggle for commons is the action necessary to bring out the true desires of each person, set free from market constraints and manipulation, as well as from State addresses; and is re-oriented toward categories of commons as non-exclusive and relational. This means that 
the commons, regardless of their public or private membership, express utility that is functional to the exercise of fundamental rights and the free development of the people; therefore, their collective enjoyment needs to be ensured, directly and by all, even for future generations.

The topic of common areas has risen in attention as of the so-called "tragedy of the commons" [4], a theory which argues there will be an inevitable depletion of resources due to the fact that every user becomes the only owner of the private benefits obtained from the resource, but he shares with the whole community the collective costs of the depletion. The debate arising from the Hardin statements found an interesting position as seen by the political scientist Elinor Ostrom, by which, instead, many communities are likely able to avoid the loss and degradation of the common property without the need for intervention from either the public or private side. In her book 'Governing the Commons', Ostrom has indeed shown how often both public and private management are unsuccessful, responding, more precisely, to three models: the "tragedy of the commons" [4], the "prisoner's dilemma game" [5], and the "logic of collective action" [6]. According to all of these theories, there will be (and there are already) tragic consequences (up to the real disappearance of the resource) caused by the common use of an asset without the intervention of a public or a private institution. The aim of the Elinor Ostrom study was therefore to demolish the belief of many that the only way to solve the problems of common resources is to impose an external authority, both by centralization and privatization [7]. The Ostrom theories open a new way of looking at things and allow us to overcome the dichotomy between public and-private where we started. Most of the cases studied by Ostrom are, in fact, articulated combinations of public and private instruments.

\section{WATER AS A COMMON GOOD}

Also, the territory involved, the physical space where a community lives thanks to the common use of water from existing resources founded on it, falls within the definition of common areas. The territory is intended not as a mere aggregation of different elements, but as a system in which are intrinsically intertwined both nature and history, heritage to be preserved and social needs to be met; as a system that can be understood, defended and transformed only if it is considered as the whole of its aspects and components [8].

Water is a basic element of a territory: it is a natural resource and the access to water is an essential human right, not just a need. This right is cancelled when the water is treated as a commodity to be privatized, rather than as for the common good [2].

Water is considered a common not only as 'material' resource and basis for human existence, but also as a source of metaphysical symbolism, aesthetic pleasures and therapeutic values [9]. It would be difficult to separate, regarding water, the physical traits from the social ones, the natural aspects from the cultural ones.

The notion of commons, in the past limited to sustenance and necessities, is expanding to be resources not strictly related to immediate subsistence.

The evolution of the bath concept, closely linked to the relationship between water and man, should be understood in its two main forms: one as devoted exclusively to cleaning (easy ablution, 'basic necessity') and the other intending the bath as regeneration. Deeply connected with the type of bath is its social significance: the bath with the only purpose as cleaning is a private and individual matter; the types intended as regeneration favors, historically, social relationships and represents a focus for the associated and communal life [10].

Thermal baths belong to this second type of bath, because they translate, through different forms, local traditions and identities. It is in this light that we can see the baths as 
commons that are able, on the one hand, to set in motion relational exchanges, to follow the desires and motivations of the people and meet its needs; while on the other hand, to generate in the population a psychological attachment to the places, values and practices of a community [11]. This activates, within the territory, new mechanisms, new relationships between its components, balanced relations between what is public and what is private, what is natural and what is built; but above all, it really makes the population belong to the community and to the places of life, in order to make it responsible and aware of the importance of water as a resource that is not to be wasted.

The hot springs in many parts of the world are already characterized by a type of use and management in common, the so-called 'free thermal baths'. Sites like natural ponds, swimming pools and marine bays, are always frequented for their beneficial properties that are recognized in a more or less scientific way, and that are able to establish deep-rooted links with the territory. This is an atypical offer, since it lacks a real thermal structure, consisting of hot springs with free access or with a reduced entrance fee (just enough to be able to pay the costs of cleaning and maintenance services, usually performed by small local cooperatives) and which exploit the water not yet, or not at all. These types of thermal opportunities, often overlooked, are of interest for establishing ties with the place, with the local communities and for the high landscape value context where the flow of the springs or free thermal baths can be found in the woods, by the sea, in the hills. They are 'spaces' of natural water.

"The baths without establishment in restricted economic times, are a heritage for Italy: in addition to the savings, they lead to the luxury of freedom" [12].

\section{THE THERMAL SYSTEM OF SARDINIA}

Before dealing with the topic of how the thermal places in Sardinia respond or could respond to the logic of the common areas, it is essential to discover the island's thermal system, to investigate both the environmental and territorial structure, as well as the cultural-historical one; observe its relationship with the surrounding territory and in relation to other landscape variables; and understand in what form the waters are born and how they are then exploited by man.

The thermal springs distributed around the territory of Sardinia reveal their ancient origins with very different characteristics: the more established and still functioning sites, archaeological remains, and point elements scattered throughout the landscape represent the memory of structures that over the centuries have created important opportunities to generate community spaces. There are numerous traces of this ancient history: from the springs of 'Santa Maria de is Aquas' near Sardara, where are located the sacred nuraghe and well, dating back to $1600 \mathrm{BC}$, which were later denominated Aquae Neapolitanae by the Romans; to the Fordongianus site, whose name derives from the ancient Roman town of Forum Traiani and which replaced the older one of Aquae Hypsitanae, the mineral springs located at the river Tirso, of which today we can admire the remains of thermae dating from the imperial period [13].

The geological history of Sardinia is a complex matter too: Sardinia is a region of Italy that presents great geodiversity, and it is one of the most promising for the exploitation of geothermal resources and for the presence of numerous geothermal springs. It is second only to Tuscany.

The origin of the warm waters of Sardinia is to be found in a geothermal gradient, which leads to a deep infiltration of rainwater and to its subsequent upwelling through the faults. Upwelling, which takes place in a so fast manner, does not allow water to rebalance its temperature. It is for this reason that the waters come out still hot. In Sardinia, there are 
mainly two kinds of completely different waters: those that flow from granites (thus are warmer) and those that flow from the vulcanites (colder). This difference in temperature and water quality generates variations in the type of thermal landscape.

Where the water pours out from faults surrounding the basins and the ample plains, the thermal landscapes are 'flat' landscapes (e.g. Benetutti, Sardara); in the case of faults in the vicinity of horst (therefore waters that flow from vulcanites), we find thermal landscapes such as Casteldoria, characterized by a more complex topography [14]. Today, however, the historical and cultural as well as the landscape value of the traces, so stratified over the centuries, does not match the effective exploitation and enhancement of thermal resources. Many elements connected to the resource appear as mere abandoned archaeological remains and the main thermal structures, although still active, are not actually giving connotation to the area, being unable to establish strong relationships with the context in which they are located, to constitute fundamental components of an overall integrated and structured system, as well as to stimulate in their local communities a sense of place attachment. It is within this framework that it is fundamental to recall the concept of territory as a system made up of interwoven elements; it appears there is currently the need to create a 'network' able to characterize the territory itself. The thermal baths should not be treated as isolated elements, but as opportunities for enhancement of the whole context. A first initiative in this direction is represented by the desire of some municipalities of Sardinia to form a 'Sardinian Thermal System', aimed toward the promotion and incentives for development of the thermal baths and geothermal energy in the region, and involved in the proposition of a new law to revise the outdated laws currently in force.

At this stage of the legislative impasse, the initiative by only public institutions does not seem sufficient to create a system that is really able to bring new development to the territory; and consequently, to the communities that live in these territories and at the same time to preserve the water resource. It is necessary to promote a deeper involvement process of the population inhabiting the territories, to make them aware of the resources that they have in place, both in terms of 'immediate' or direct use, for healing/regenerative purposes and in terms of 'mediated' tourism use.

\section{FORDONGIANUS, DORGALI, BENETUTTI}

The thermal system of Sardinia is characterized by the different contexts in which the water resources are used, managed, and enjoyed through its different forms; however, not in all of these sites is the water treated as a common good to be taken care of, but rather as a commodity to be exploited in structures and in ways that are often unsuitable for forging relationships with the places and the communities. We chose to analyze three sites, characterized by quite different contexts, but which share a 'sensitive' management that ensures the respect of the thermal water: Fordongianus and its historical town of ancient origin, Dorgali and its surroundings of great environmental interest, and Benetutti and its widespread agricultural landscape.

In Fordongianus, the site more consolidated from the historical and urban point of view, the evidence of the Roman presence dates back to the late republican times and concerns both the exploitation of hot waters for therapeutic purposes and the strategic layout of the castrum (in order to contain the raids of inland populations).

The Romans changed the original name of the town called Aquae Hypsitane into Forum Traiani; improved the road network; and built aqueducts, thermal baths, an amphitheater, and the bridge over the river Tirso. The urban fabric, nowadays, follows the track of the 


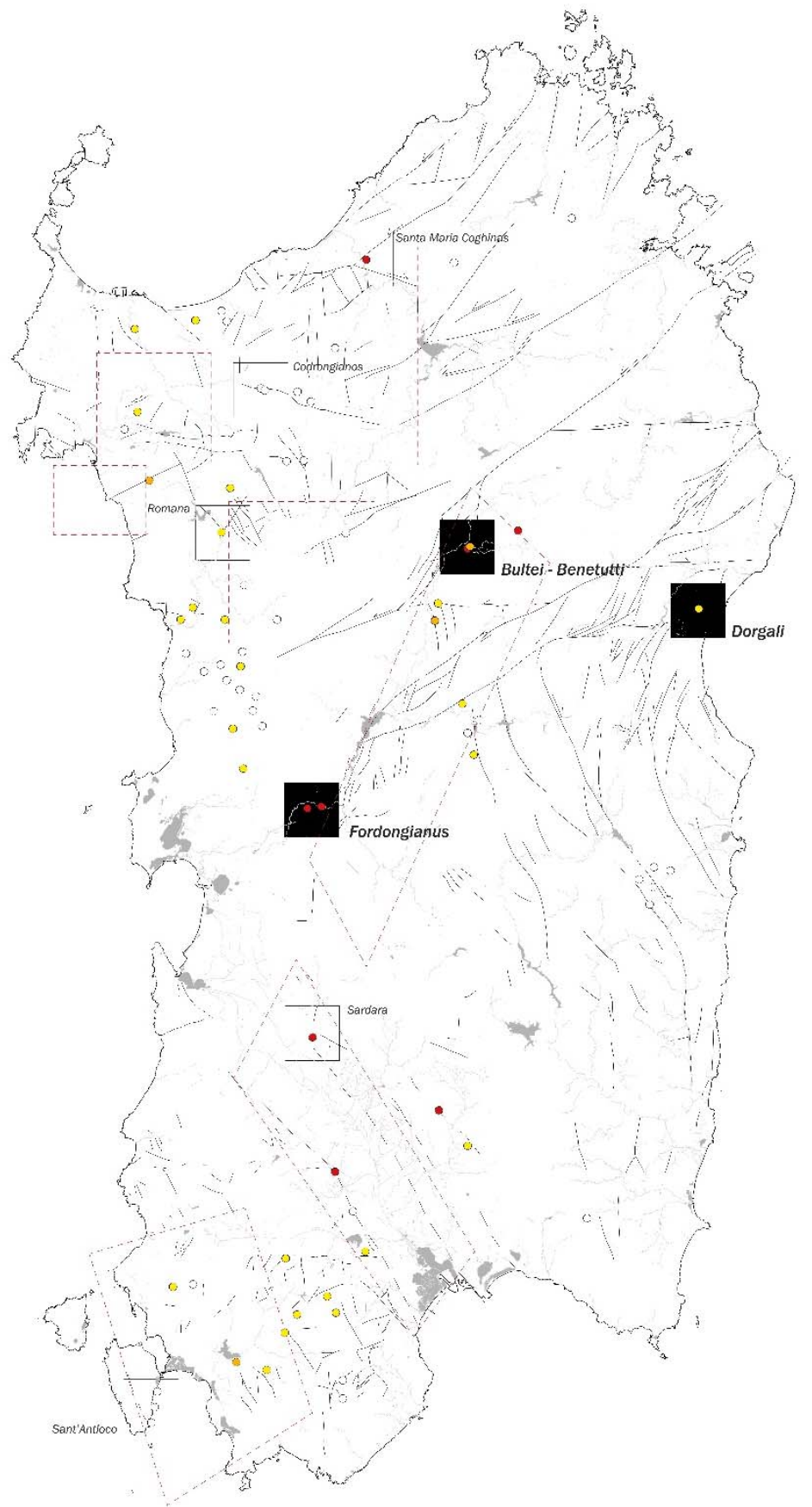

Figure 1: Map of the 'Thermal System' of Sardinia. Black squares are selected study cases; red to white dots are springs' temperature indicators, from hyper-thermal to cold. 
roman castrum based on cardo and decumanus, which we can find in the main roads of the town. Fordongianus, founded along the Tirso river bank, has grown over time in an almost homogeneous way on all fronts, until reaching the natural limit constituted by the river itself which still represents a barrier for the town; and is underlined by the presence, in its vicinity, of the Roman baths ruins [15].

Concerning the thermal resources there are two springs, one called 'del fegato' (the liver) and the other 'del bagno' (the bath): the Caddas spring, located on the left bank of the river Tirso, and Banzos, a smaller spring. Part of the water flows near the archaeological ruins of the Roman thermal complex of the imperial age. This first historical cultural meeting mode with a thermal resource is a valuable element, and it makes Fordongianus a unique site in the landscape of the island.

A second thermal environment regards the thermal establishment complexed with an annexed hotel, where the thermal water is exclusively exploited for purposes related to health and well-being. But in a system so complex, the most interesting perspective is the presence of the free thermal baths of Is Bangius.

In this case, the water originates from a real thermal canal, which where it meets with the river Tirso permits obtaining access to three comfortable, small pools: these are filled with warm water in a completely natural environment. These three small pools are housed in a structure built in 1800 on the left bank of the river and recently restored. To dive in these tanks it is possible to pay a few Euros to the Forum Traiani Cooperative that manages and takes care of them, looking after access, cleaning and maintenance.

In the Dorgali site is where the thermal spring of San Giovanni Su Anzu, known since Roman times, finds its first written record in the Vittorio Angius dictionary, Città e Villaggi della Sardegna dell'Ottocento (1833-1836), where is described a well and "a loggia with two small rooms." Witness-confirmed by a 1954 map in which it is still clearly visible, there was a small rectangular building constructed to support the thermal spring [16]. The main thermal building's evolution takes place, in fact, in the fifties of the twentieth century, when the population of the small town of Dorgali rediscovered this place that was for some time forgotten. With the economic and practical support of the inhabitants of Dorgali, it has been built onto with a new volume that expands the covered space of the two rooms available. In the following years the structure was again abandoned until, in the early nineties, a man called Agostino, a willing shepherd born and raised in Dorgali, becomes the guardian of the Lapia (the tub), which then re-earns its function and becomes a symbol for the entire area, used by both local community and tourists, for both rehabilitative exercises and for simple moments of relaxation when returning from work or from the nearby beaches and main tourist destinations.

This small thermal building is set in a unique landscape system, characterized both by natural elements, such as the Rio de Su Anzu (Su Anzu small river) that runs through the site and to the nearby cave of San Giovanni, embedded within the mountain system of Monte S'Osplile; and by anthropic factors, such as the Church of Giovanni (seventeenth century) and some country houses with typical local architecture.

Certainly, the most significant environmental characteristic of the local environment is recognized in the karst system Su Anzu-Ispinigoli, which is connected to the water system. Regarding the natural, cultural and social areas of these different components, we describe the great potential of this site: The structure that houses the tanks and the annexed dressing room needs a proper renovation. The inhabitants of the nearby village of Dorgali and various organized groups have already demonstrated in the past their affection and attachment to this place with a strong identity-value, through their voluntary, free small maintenance works . 
Finally, in Benetutti, the landscape is dominated by the plain of San Saturnino (from the name of the church, which was inhabited and exploited since ancient times for the presence of thermal waters). The vast and fertile plain in which flowed the Riu Mannu and Tirso rivers has been, since ancient times, an ideal place to build a village, or perhaps a town, that took the name of Lesa. Currently the relative population, while occupying the plain, well understands the importance and value of the waters, which originally took the name from the acquae Lesitanae. The city must have assumed an important role in the Roman period, as Ptolemy in his writing remembers the effectiveness of its waters and enhanced therapeutic value. Still, today the names of the different springs have been handed down by tradition, related to the diseases or organs that the waters would cure [17]. Today, the thermal area lies between the small towns of Benetutti and Bultei, and has some features that make it a unique place: in addition to traditional spa structures that exploit the healing properties of the water, the area is scattered with various outdoor natural tanks where it is possible to dive freely .

The small pools, even if located in some cases within private grounds, are absolutely accessible and usable by everyone. The use of the tanks by the local community is managed accurately, although there are no written rules: in the tanks it is possible to soak no more than 15 minutes, and when they are already occupied (a fact easily recognizable by the use of hanging clothes in the bushes around the tanks) it is necessary to wait for your own turn at a safe distance, so as to not disturb the privacy and relaxation of the others. The tanks are characterized by varying states of preservation, but in any case, they create from time to time unique 'environments' where one can have a thermal bath experience in close contact with the landscape: from the Roman calidarium evidence of an ancient past, to the stone tank immersed in the countryside, where tourists and locals give themselves a few minutes in close communion with nature, to the small tub inside a ruin where they bathe looking for free benefits.

\section{THREE VARIATIONS OF THERMAL WATER AS A COMMON GOOD}

In each of these places, therefore, water is considered a common resource and is managed according to three different modes that reflect the physical-environmental characteristics of the reference landscape and the distribution of the thermal springs within this landscape.

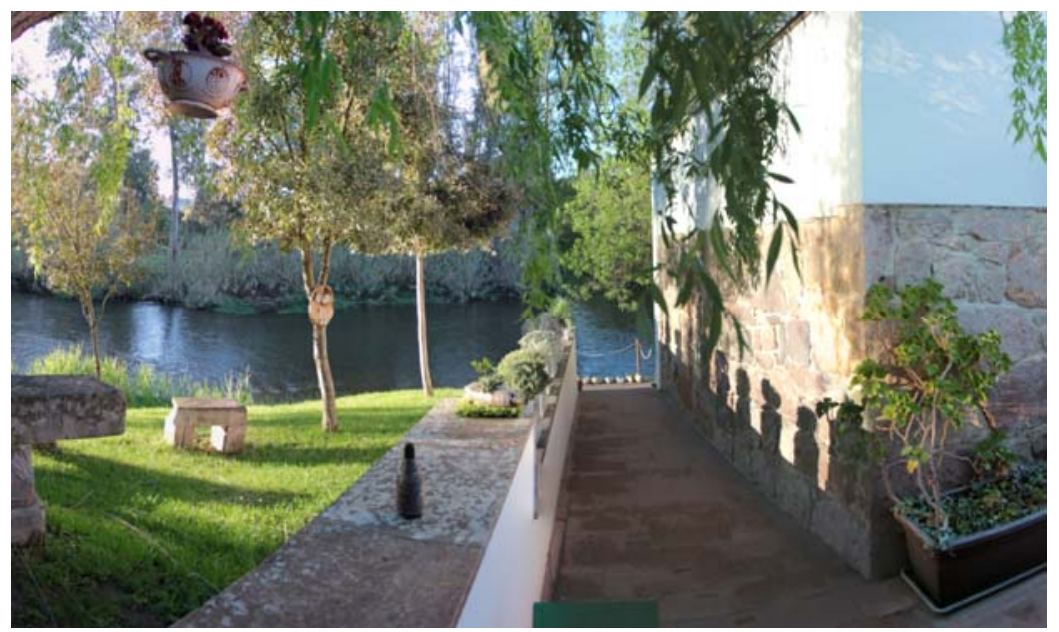

Figure 2: A view of the free thermal baths along the Tirso river in Fordongianus. 


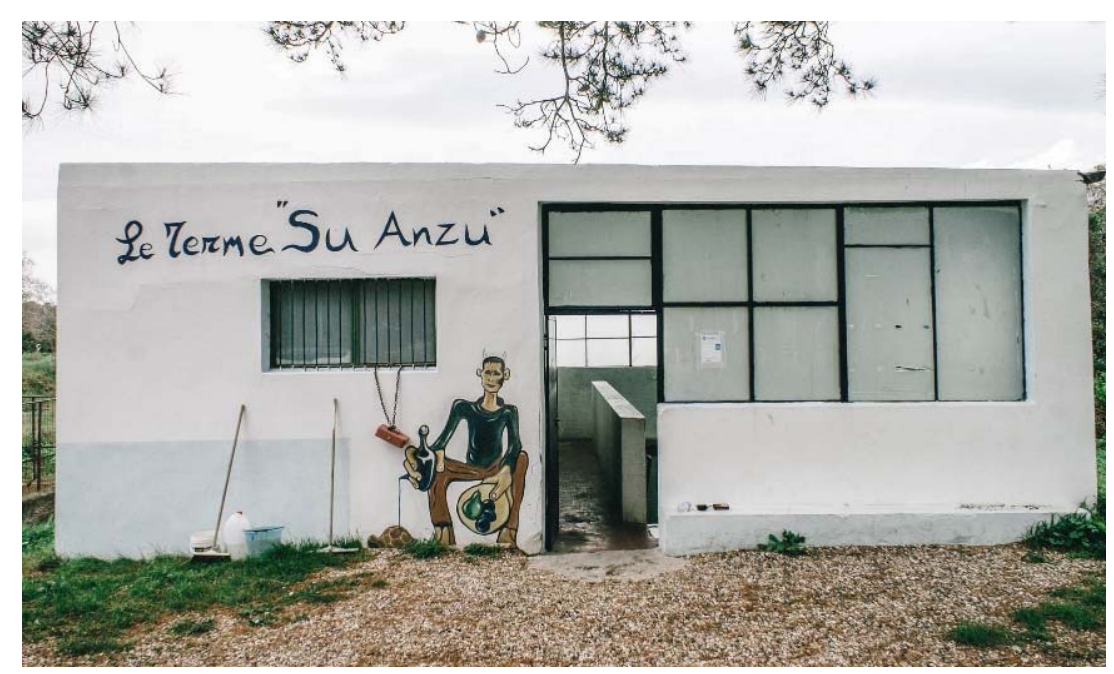

Figure 3: A view of the small building for thermal baths in Dorgali.

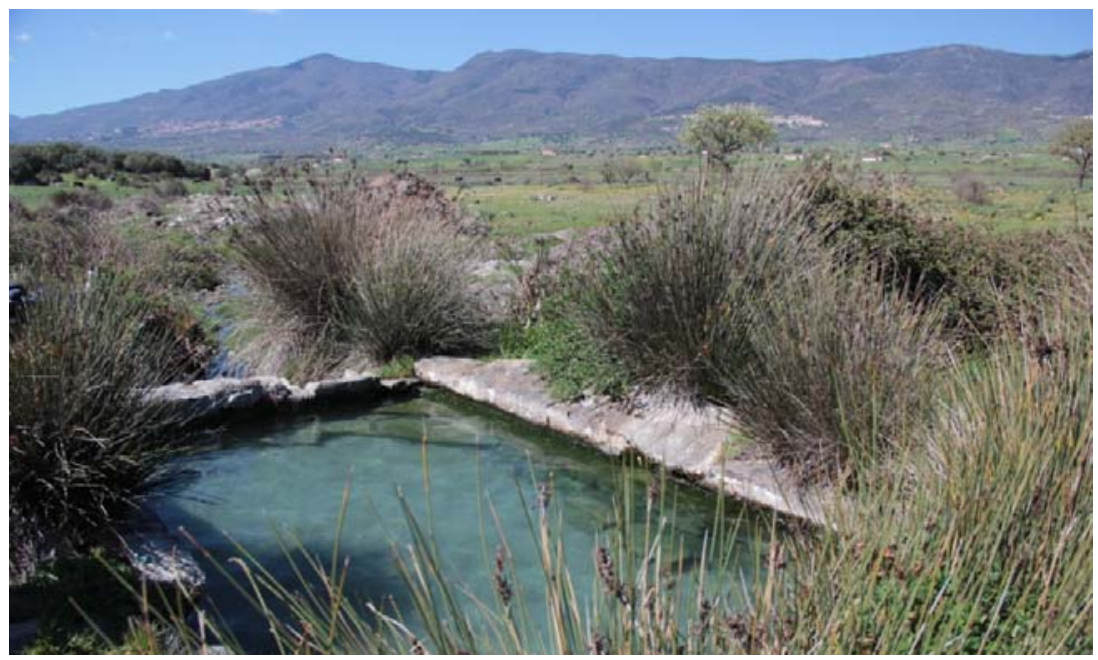

Figure 4: A view of one of the outdoor natural tubs in Benetutti.

The three cases are characterized and presented according to the growing degree of freedom in which it is possible to use the water resource. In the case of Fordongianus, the two springs are located in the vicinity of an urban-historical context and affected by the larger tourist flows; the thermal resource, while respecting the concept of being common, has the need for a structured and organized management as in the case of a cooperative. 
The Dorgali spring flows, instead, in a more 'cosy' and domestic landscape and interacts with the system of caves and the agricultural landscape. It is, therefore, a small system experienced by a cohesive community, and where the thermal resource can also be handled by one person, a representative of the values and wishes of the community.

In Benetutti, the territory has a diffuse structure of which the many hot springs are substantial components. The thermal landscape is so complex and varied that its management is left free to be accomplished spontaneously, through practices originated from the experience: real social conventions not being imposed from above, 'from the outside'.

These places are just a few examples of the varied and extensive landscape that characterizes the thermal landscape of the region; starting from the study of these contexts, it looks possible to think of an implementation of a Sardinian thermal system, based just on considering thermal water as a common good.

Local dimension (specific place and time); global dimension (universal accessibility); the coexistence of nature and culture (tangible and intangible aspects), sharing the resource and its use in common by the community; social organization based on community and interpersonal solidarity; indifference to public or private property (a direct relationship between good and the entire community) are all distinctive elements of the commons that can easily be seen in the analysed study cases.

In light of these considerations, it is clear that the thermal resource should not be treated as a simple object, a mere property, a commodity from which to profit until exhaustion, but as a common good recognising these features that already inherently are owned and proposing diversified and coherent systems of management that are able to include and foster the local practices which this paper has tried to highlight.

\section{REFERENCES}

[1] Aristotle, Book II. Politics, eds. F. Pezzoli, M. Curnis, L'Erma di Bretschneider: Rome, 3, 2012.

[2] Ricoveri, G., Nature for sale: The Commons Versus Commodities, Pluto Press: London, 2013.

[3] Mattei, U., Beni comuni: un manifesto [Communal Benefits: A Manifesto], Editori Laterza: Rome and Bari, pp. 52-53, 2011.

[4] Hardin, G.R., The tragedy of the commons. Science 162, pp. 243-248, 1968.

[5] Dawes, R.M., Formal models of dilemmas in social decision-making. Human Judgment and Decision Processes, eds. M.F. Kaplan, S. Schwartz, Academic: New York, pp. 88-107, 1975.

[6] Olsen, M., The logic of collective action, Harvard Press: Cambridge, 1965.

[7] Ostrom, E., Governing the commons: the evolution of institutions for collective action, Cambridge University Press: Cambridge and New York, 1990.

[8] Salzano, E., L'habitat dell'uomo bene comune in la società dei beni comuni: una rassegna [Men's common good habitats in the society of common good: a review], ed. P. Cacciari, Ediesse: Rome, pp. 87-93, 2010.

[9] Wylson, A., Aquatecture, The Architectural Press: London, p. 3, 1986.

[10] Giedion S., Mechanization takes command: a contribution to anonymous history, Oxford University Press: New York, 1948.

[11] Inghilleri, P., Verso un'architettura dei beni comuni e dell'identità, Lotus, pp. 44-49, 2014. 
[12] Rolle, C., Terme libere: gratis e 'trendy'. Corriere della sera, 2014, Online. http://viaggi.corriere.it/viaggi/weekend/terme-libere-gratis-trendy-4e50942e-9b1e11e3-8ea8-da6384aa5c66/. Accessed on: 24 Mar. 2017.

[13] Mastino, A., Storia della Sardegna Antica [The Story of Ancient Sardinia], il Maestrale: Nuoro, 2009.

[14] Cuccuru, S., Oggiano, G. \& Funedda, A., Low Enthalpy Geothermal suitability of North Sardinia (Italy). Energy Procedia, 76, pp. 256-263, 2015.

[15] Zucca, R., Fordongianus, Carlo Delfino Editore: Sassari, 1986.

[16] Angius, V. \& Casalis, G., Dizionario geografico storico statistico commerciale degli stati di s. m. il re di Sardegna [Historical geographical dictionary of comercial statistics of the state of Sardinia], ed. Anastatica, Editrice Sardegna: Cagliari, 1995.

[17] Fenu, A., La Piana; le Terme, la chiesa di San Saturnino: storia, leggende, contese [The plain, the thermal baths, the church of San Saturnino: stories, legends, contests], Ramagraf: Ozieri, 2010. 